\title{
Dynamics of the Cardiovascular System and Heart Rhythm Optimization
}

\author{
Kodkin Vladimir* and Khafizova Anastasia \\ Institute of Sport, Russia \\ *Corresponding author: Kodkin Vladimir, Institute of Sport, Russia
}

\section{ARTICLE INFO}

Received: February 19, 2019

Published: 㓞 March 05, 2019

\section{ABSTRACT}

Keywords: Electrocardiography; Heart Rate; Computer Appliance; Speed of Ventricular Activation; Optimal Functional State of the Cardiovascular System

Citation: Kodkin Vladimir, Khafizova Anastasia. Dynamics of the Cardiovascular System and Heart Rhythm Optimization. Biomed J Sci \& Tech Res 15(3)-2019. BJSTR. MS.ID.002713.

\section{Introduction}

Parallels between the cardiovascular system and systems of automatic control have been established several decades ago by numerous scientists [1,2]. This results in several problems, the main of which can be formulated in the following way:

a) Automatic control systems with a carrier frequency are mostly belong to non-linear and non-stationary systems, i.e. those systems, whose characteristics depend significantly on external conditions and this carrier frequency.

b) Such systems should possess optimal states [3]. These states adjust the system to certain conditions and tasks with respect to the optimality criterion.

\section{Materials and Methods}

Comparing CVS and a non-linear automatic control system, it should be noted that one of the most effective and descriptive tools of the study for such systems is the method of phase space or phase plane. It consists of the analysis of synchronous diagrams of any variable (ECG) and its first time derivative (speed ECG). One of the examples of such methods is the analysis of the Speed of Ventricular Activation (SVA). According to the definition proposed by Volkova et al. [2], SVA is considered as the ratio of the maximum ECG derivative (speed ECG) to the ECG value now corresponding to this maximum derivative

$$
S V A^{*}=\frac{\stackrel{\square}{R_{m}}}{R\left(\stackrel{\square}{R}_{m}\right)}
$$

The authors of the SVA method, while working with ECG signals from simple electrocardiographs with standard scales, could not register the moment of time corresponding to the maximum derivative and its ECG value. Therefore, they calculated SVA as the ratio of the maximum derivative to the maximum ECG value (R-wave).

$$
S V A=\frac{R_{m}}{R_{m}}
$$

For a non-linear system of automatic control both parameters could be important. Calculated and synchronized with ECG and HR they could be a multi-loop diagram of the functional state of the cardiovascular system, which will help to identify the system and indicate the ways of its optimization [3]. SVA and SVA* were measured in athletes under ergometric load using detailed R-wave electrocardiogram of high precision, which was obtained with the help of the continuous ECG monitoring developed in SUSU [4-6]. In the first athlete SVA* value was changing together with HR under increasing and decreasing loads, however his HR value was no more than $120 \mathrm{bpm}$, while other athletes demonstrated HR of 150 bpm or even $180 \mathrm{bpm}$ under similar load. 


\section{Results}

These observations allowed us to state a hypothesis on the optimal compensation of long-term loads, which results in the lowest HR increase and in the greatest SVA* growth. As follows from the diagram of SVA*, its maximal growth is registered in the points corresponding to $\mathrm{HR} \approx 68-70 \mathrm{bpm}$ both under increasing

and decreasing load, i.e. $\frac{d(S V A)}{d(H R)}$ has its maximum under $\mathrm{HR} \approx 68$ $70 \mathrm{bpm}$. It means that under these frequencies load compensation in the athlete's body occurs with a minimum HR growth. For other

SVA* trends we can define maximum values of $\frac{d(S V A)}{d(H R)}$ under HR $\approx$ 90-95 bpm.

\section{Summary}

The experiments and their analysis revealed that CVS can be close to non-linear automatic control systems and particularly, to the systems with carrier frequency, whose role is performed by HR. Optimal criteria can be formulated for optimal HR in certain conditions for the performance under long-term physical load.

\section{Acknowledgement}

The work was supported by Act 211 Government of the Russian Federation, contract No 02.A03.21.00.

ISSN: 2574-1241

DOI: 10.26717/BJSTR.2019.15.002713

Kodkin Vladimir. Biomed J Sci \& Tech Res

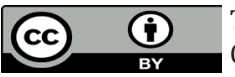

This work is licensed under Creative Commons Attribution 4.0 License

Submission Link: https://biomedres.us/submit-manuscript.php

\section{References}

1. Baevsky RM (2016) Heart rate variability in space medicine. Proceedings of the VI All Russia Symposium with international participation dedicated to the memory of Academician Vasily Vasilievich Parin 15-20.

2. Levashova O, Levashov S (2016) Non-invasive diagnostics of the functional state of the myocardium in children-athletes based on analysis of velocity characteristics of electrical activity of the heart. Science and sport bulletin of Ural and Siberia 4(12): 26-34.

3. Kodkin VL (2017) Method for synthesis of high-accuracy dynamic nonlinear control system. Proceedings of SPIE - The International Society for Optical Engineering 10376: 11.

4. Smirnov AS, Erlikh VV, Kodkin VL, Keller AV, Epishev VV (2016) Noncontact ECG monitoring. Progress in Biomedical Optics and Imaging Proceedings of SPIE.

5. Kodkin VL, Yakovleva GV, Smirnov AS (2017) Continuous Control Systems for Non-contact ECG. Progress in Biomedical Optics and Imaging Proceedings of SPIE.

6. Kodkin VL (2017) Developing a system for continuous control of the functional status based on recording of electrical potentials and acoustic signals. International Conference on Advances in Biomedicine and Biomedical Engineering 6th International Conference on Biotechnology and Bioengineering ICABBE $\& 6^{\text {th }}$ ICBB Offenburg Germany September p. 26-28.

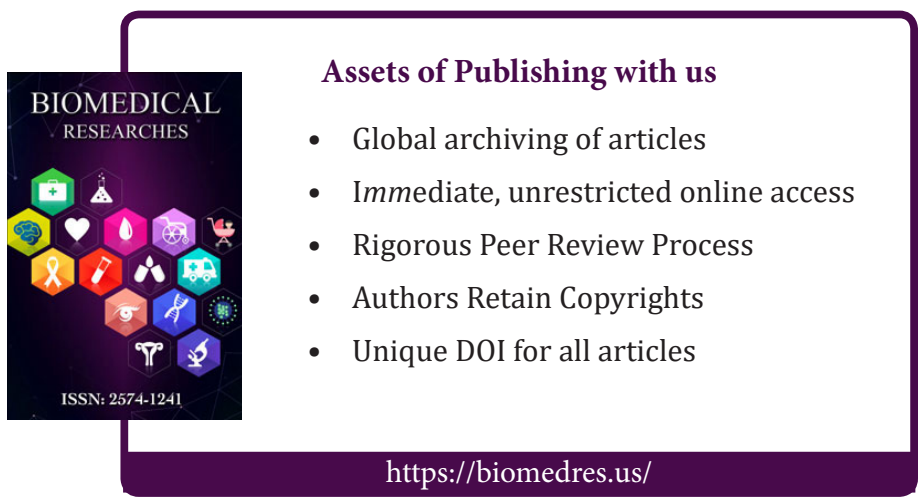

